\title{
Simulation and Optimization of Throttle Flowmeter with Inner-Outer Tube Element
}

\author{
Jiang Meng ${ }^{1}$, Zhipeng Liu ${ }^{1}$, Kun $\mathrm{An}^{2}$, Meini Yuan ${ }^{3}$ \\ ${ }^{1}$ School of Mechanical \& Power Engineering, North University of China, Taiyuan, 030051, China \\ ${ }^{2}$ School of Computer Science \& Control Engineering, North University of China, Taiyuan, 030051, China \\ ${ }^{3}$ School of Mechatronic Engineering, North University of China, Taiyuan, 030051, China \\ Corresponding author: Jiang Meng, Email: johnmeng@nuc.edu.cn
}

In order to solve the dilemma between the smaller pressure loss and the larger flow measurement signal in traditional throttle flowmeters, a throttle structure with the inner-outer tube was designed and analyzed. The mathematical relationship model deduced from hydrodynamics showed there were three major parameters to determine the designed throttle structure. Furthermore, the optimal results were achieved by combining orthogonal test design and computational fluid dynamics by taking the ratio of differential pressure of inner-outer tube divided by that of anterior-posterior tube as the optimization goal. Finally, the simulation results with the best level parameters showed that the differential pressure of the anterior-posterior throttle could remain not only the smaller value among other parameters with the same structure of inner-outer tube. On the other hand, it was about one order magnitude less than differential pressure of V-cone flowmeter in the similar installation conditions with the flow velocity varying from 0.5 to $3.0 \mathrm{~m} / \mathrm{s}$. The designed inner-outer tube flowmeter can not only save manufacture costs, but also avoid the large sensitivity of pressure sensors, which may lead to a broader application in chemical and petrochemical enterprises.

Keywords: Throttle flowmeter, inner-outer tube, pressure loss, range analysis, computational fluid dynamics.

\section{INTRODUCTION}

As a measuring tool in modernized production coexisting with energy crisis, more and more professions depend on the flow measurement, such as mechanical ventilation [1], multi-phase analysis [2], and viscous fluid measurement [3], etc. With the development of economy and industry, more and more requirements are put forward to measure flows with high precision and great efficiency [4]-[5] based on the measuring laws, the measured fluids and the installation conditions.

The differential pressure flowmeter (DPF) [6]-[7] is one of the most widely used flow instruments rooted in the throttle effect, where the throttle differential pressure is proportional to the volume flow square. Both standard orifices and nozzles are popular types of throttle flowmeters, which were applied in industrial production because of easy production, low cost and no calibration under standard conditions. However, the traditional DPF has a smaller range ratio, bigger loss of pressure and higher requirement of field installation, and these shortcomings restrict seriously the broad application of throttle flowmeters. Therefore, researchers have designed and developed many new types of flowmeters, such as spindle, Venturi tube [8]-[9], and Vcone flowmeters [10].
The pressure loss is quite an important factor to evaluate performance of the throttle flowmeter [11]-[12]. On one hand, it is related to the energy consumption where the smaller pressure loss means less energy to be transported than normal to the equal distance. On the other hand, the differential pressure of the throttle element is used to measure the velocity or volume flow, where the bigger value is required to improve the flowmeter sensitivity. There occurs a dilemma between the fluid transportation and the flow measurement for traditional throttle flowmeters.

To solve this problem, a modified flowmeter called the inner-outer tube throttle flowmeter, was designed and simulated in this paper. Different from the V-cone flowmeter, two pressure pores were located in the straight section to measure the differential pressure signal between the inner-outer tube, rather than the anterior-posterior throttle, which can not only bring less throttle effects on the pressure drop, but also provide more stability of the pressure signals and better economy with the designed structure of the inner-outer tube. Therefore, the modified flowmeter is worth studying further both theoretically and in simulations.

\section{THEORETICAL FOUNDATION}

Considering the complexity of the flow, three hypothesis conditions are listed as follows: 
1). The flow is supposed to satisfy the laminar cases;

2). Any flow line does not change from Area 1-1 to 2-2;

3). The thickness of pipeline can be regarded as 0 .

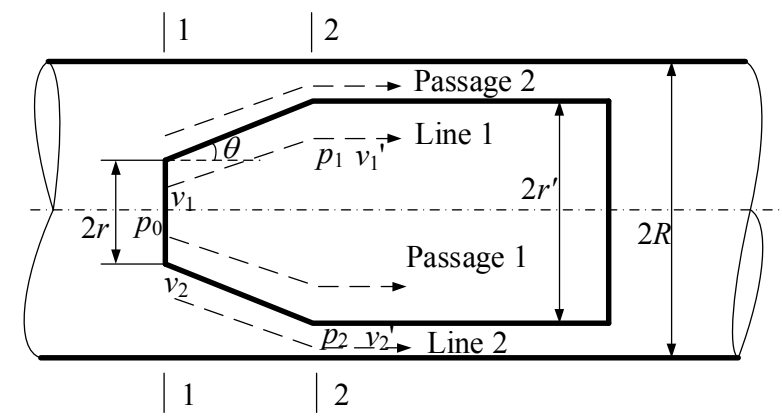

Fig.1. Structure of modified inner-outer tube throttle flowmeter.

According to the Bernoulli principle, Lines 1 and 2 (Fig.1.) satisfy the following equation,

$$
\begin{aligned}
& \frac{p_{0}}{\rho}+\frac{v_{1}^{2}}{2}=\frac{p_{1}}{\rho}+\frac{v_{1}^{\prime 2}}{2}+w_{f 1} \\
& \frac{p_{0}}{\rho}+\frac{v_{2}^{2}}{2}=\frac{p_{2}}{\rho}+\frac{v_{2}^{\prime 2}}{2}+w_{f 2}
\end{aligned}
$$

where $\rho$ is the fluid density, $\mathrm{kg} / \mathrm{m}^{3} ; p_{0}$ is the absolute pressure of 1-1 section, $\mathrm{Pa} ; p_{1}$ and $p_{2}$ are the inner and outer pressure in 2-2 section, $\mathrm{Pa} ; v_{k}$ and $v_{k}^{\prime}$ are the inlet and outlet velocity of Line $k(k=1,2), \mathrm{m} / \mathrm{s} ; w_{f 1}$ and $w_{f 2}$ are the viscosity losses of Line 1 and $2, \mathrm{~J} / \mathrm{kg}$.

Equations (1) and (2) can be changed into the average velocity expressions, respectively:

$$
\begin{aligned}
& \frac{p_{0}}{\rho}+\frac{\bar{v}_{1}^{2}}{2}=\frac{p_{1}}{\rho}+\frac{\bar{v}_{1}^{\prime 2}}{2}+\bar{w}_{f 1} \\
& \frac{p_{0}}{\rho}+\frac{\bar{v}_{2}^{2}}{2}=\frac{p_{2}}{\rho}+\frac{\bar{v}_{2}^{\prime 2}}{2}+\bar{w}_{f 2}
\end{aligned}
$$

where $\bar{v}_{k}$ and $\bar{v}_{k}{ }_{k}$ is the inlet/outlet average velocity of Line $k(k=1,2), \mathrm{m} / \mathrm{s} ; \bar{w}_{f 1}$ and $\bar{w}_{f 2}$ are correspondingly the average viscosity losses of Lines 1 and $2, \mathrm{~J} / \mathrm{kg}$.

Therefore, the differential pressure of the inner point $p_{1}$ and the outer point $p_{2}$ can be calculated:

$$
\begin{aligned}
\Delta p= & p_{1}-p_{2} \\
= & \frac{\rho}{2}\left[\left(\bar{v}_{1}^{2}-\bar{v}_{1}^{\prime 2}\right)-\left(\bar{v}_{2}^{2}-\bar{v}_{2}^{\prime 2}\right)\right] \\
& -\left(\bar{w}_{f 1}-\bar{w}_{f 2}\right) \\
= & \frac{\rho}{2}\left[\left(\bar{v}_{1}^{2}-\bar{v}_{1}^{\prime 2}\right)-\left(\bar{v}_{2}^{2}-\bar{v}_{2}^{\prime 2}\right)\right] \\
& -\rho g\left[\left(h_{\lambda 1}-h_{\lambda 2}\right)-\left(h_{\zeta 1}-h_{\zeta 2}\right)\right]
\end{aligned}
$$

where $h_{\lambda 1}$ is the route loss of Line $1, \mathrm{~J} / \mathrm{kg}$, which can be calculated by the route loss equation of straight pipe when the flow passage is not very long,

$$
h_{\lambda 1}=\frac{8 \mu l}{\pi \rho g} \cdot \frac{q_{v 1}}{r^{4}}
$$

and $h_{\lambda 2}$ is the route loss of Line $2, \mathrm{~J} / \mathrm{kg}$, whose equation is based on the route loss equation of different diameter pipe,

$$
h_{\lambda 2}=\frac{8 \mu l}{\pi \rho g} \cdot \frac{q_{v 2}}{R^{4}-r^{4}-\frac{R^{2}-r^{2}}{\ln (R / r)}}
$$

$h_{\zeta 1}$, the local loss of Line 1, which can be obtained based on the diffuser tube equation,

$$
h_{\zeta 1}=\varphi \frac{\left(\bar{v}_{1}-\bar{v}_{1}^{\prime}\right)^{2}}{2 g}
$$

and $h_{\zeta 2}$ is the local loss of Line 2, which can be calculated according to the nozzle tube theory,

$$
h_{\zeta 2}=\zeta \frac{\left(\bar{v}_{2}-\bar{v}_{2}{ }^{\prime}\right)^{2}}{2 g}
$$

where $l$ is the length of flow passage, $\mathrm{m} ; \mu$ is the dynamic viscosity, $\mathrm{Pa} \cdot \mathrm{s}, q_{v 1}$ and $q_{v 2}$ are the volume flow of Passages 1 and $2, \mathrm{~m}^{3} / \mathrm{s} ; r$ is the hydraulic radius of Passage $1, \mathrm{~m} ; R$ is the pipe radius, $\mathrm{m} ; g$ is the gravitational acceleration, $9.8 \mathrm{~m} / \mathrm{s}^{2}$ normally; $\varphi$ and $\zeta$ are the different local loss coefficients, meeting the following equations,

$$
\begin{gathered}
\varphi=\frac{\lambda}{8 \sin (\theta / 2)}\left[1-\left(\frac{S_{1}}{S_{1}{ }^{\prime}}\right)^{2}\right]+\kappa\left(1-\frac{S_{1}}{S_{1}{ }^{\prime}}\right) \\
\zeta=\frac{\lambda}{8 \sin (\theta / 2)}\left[1-\left(\frac{S_{2}}{S_{2}{ }^{\prime}}\right)^{2}\right]
\end{gathered}
$$

where $\theta$ is the cone angle; $\lambda$ is the route loss coefficient of the diffuse (or nozzle) tube; $\kappa$ is the cone angle coefficient, related to $\theta ; S_{1}$ and $S_{1}$ are the area of 1-1 and 2-2 in Passage 1; $S_{2}$ and $S_{2}{ }^{\prime}$ are the area of 1-1 and 2-2 in Passage 2, seen from Fig.1.

Considering the flow passage is relatively short $(<150$ $\mathrm{mm}$ ), the values of both $h_{\lambda 1}$ and $h_{\lambda 2}$ are thus small and far less than the corresponding local losses, $h_{\zeta 1}$ and $h_{\zeta 2}$, based on (6) and (7). Therefore, the route losses can be neglected, that is, $h_{\lambda 1}-h_{\lambda 2}=0$.

According to the fluid dynamics [13], any velocity $v^{*}$ on the cross section satisfies (12) when the fluid moves in the round pipe with the radius of $R$,

$$
v^{*}=2 v_{0}\left(1-\frac{r^{* 2}}{R^{2}}\right)
$$


where $v_{0}$ is the average velocity through the cross section of pipe, $v_{0}=q_{v} /\left(\pi R^{2}\right)$, among which $q_{v}$ is the flux of the cross section with the area of $\pi R^{2} ; r^{*}$ is the radius corresponding to the velocity $v^{*}$.

Firstly, the flux $q_{v 1}$ of the inlet section $S_{1}$ in Passage 1 can be solved based on (12),

$$
q_{v 1}=\oint_{S_{1}} 2 v_{0}\left(1-\frac{r^{2}}{R^{2}}\right) d S=q_{v} \frac{2 r^{2}}{R^{2}}\left(1-\frac{r^{2}}{2 R^{2}}\right)
$$

Secondly, according to the law of mass conservation, the flux $q_{v 2}$ of the inlet section $S_{2}$ is,

$$
q_{v 2}=q_{v}-q_{v 1}=q_{v}\left[1-\frac{2 r^{2}}{R^{2}}\left(1-\frac{r^{2}}{2 R^{2}}\right)\right]=q_{v}\left(1-\frac{r^{2}}{R^{2}}\right)^{2}
$$

And then the average inlet velocities of $S_{1}=\pi r^{2}$ and $S_{2}=$ $\pi\left(R^{2}-r^{2}\right)$ are expressed respectively as,

$$
\begin{gathered}
\bar{v}_{1}=\frac{q_{v 1}}{S_{1}}=\frac{2 q_{v}}{\pi R^{2}}\left(1-\frac{r^{2}}{2 R^{2}}\right)=\frac{q_{v}}{\pi R^{2}}\left(2-\frac{r^{2}}{R^{2}}\right) \\
\bar{v}_{2}=\frac{q_{v 2}}{S_{2}}=\frac{q_{v}\left(1-\frac{r^{2}}{R^{2}}\right)^{2}}{\pi\left(R^{2}-r^{2}\right)}=\frac{q_{v}}{\pi R^{2}}\left(1-\frac{r^{2}}{R^{2}}\right)
\end{gathered}
$$

Considering the continuous equation of Passage 1 and 2,

$$
\begin{gathered}
q_{v 1}=\bar{v}_{1} S_{1}=\bar{v}_{1}{ }^{\prime} S_{1}{ }^{\prime} \\
q_{v 2}=\bar{v}_{2} S_{2}=\bar{v}_{2}{ }^{\prime} S_{2}{ }^{\prime}
\end{gathered}
$$

the average outlet velocities of $S_{1}{ }^{\prime}=\pi r^{\prime 2}$ and $S_{2}{ }^{\prime}=\pi\left(R^{2}-r^{\prime 2}\right)$ can be transformed from the above expressions,

$$
\begin{gathered}
\bar{v}_{1}{ }^{\prime}=\frac{q_{v 1}}{S_{1}{ }^{\prime}}=\frac{q_{v}}{\pi R^{2}}\left(2-\frac{r^{2}}{R^{2}}\right) \frac{r^{2}}{r^{\prime 2}} \\
\bar{v}_{2}{ }^{\prime}=\frac{q_{v 2}}{S_{2}{ }^{\prime}}=\frac{q_{v}}{\pi R^{2}}\left(1-\frac{r^{2}}{R^{2}}\right) \frac{R^{2}-r^{2}}{R^{2}-r^{\prime 2}}
\end{gathered}
$$

Finally, the following expressions can be deduced for use in the next paragraph,

$$
\begin{gathered}
\bar{v}_{1}^{2}-\bar{v}_{1}^{\prime 2}=\frac{q_{v}^{2}}{\pi^{2} R^{4}}\left(2-\frac{r^{2}}{R^{2}}\right)^{2}\left(1-\frac{r^{4}}{r^{\prime 4}}\right) \\
\bar{v}_{2}^{2}-\bar{v}_{2}^{\prime 2}=\frac{q_{v}^{2}}{\pi^{2} R^{4}}\left(1-\frac{r^{2}}{R^{2}}\right)^{2}\left(1-\frac{r^{4}}{r^{\prime 4}}\right) \\
\left(\bar{v}_{1}-\bar{v}_{1}^{\prime}\right)^{2}=\frac{q_{v}^{2}}{\pi^{2} R^{4}}\left(2-\frac{r^{2}}{R^{2}}\right)^{2}\left[1-\left(\frac{R^{2}-r^{2}}{R^{2}-r^{\prime 2}}\right)^{2}\right]
\end{gathered}
$$

$$
\left(\bar{v}_{2}-\bar{v}_{2}{ }^{\prime}\right)^{2}=\frac{q_{v}^{2}}{\pi^{2} R^{4}}\left(1-\frac{r^{2}}{R^{2}}\right)^{2}\left(\frac{r^{2}-r^{\prime 2}}{R^{2}-r^{\prime 2}}\right)^{2}
$$

And $\Delta p$ can be calculated according to (5) and (21) (24),

$$
\begin{aligned}
\frac{\Delta p}{\rho / 2}= & \frac{q_{v}^{2}}{\pi^{2} R^{4}}\left(2-\frac{r^{2}}{R^{2}}\right)^{2}\left(1-\frac{r^{4}}{r^{\prime 4}}\right)-\frac{q_{v}^{2}}{\pi^{2} R^{4}}\left(1-\frac{r^{2}}{R^{2}}\right)^{2}\left(1-\left(\frac{R^{2}-r^{2}}{R^{2}-r^{\prime 2}}\right)^{2}\right. \\
& +\frac{\varphi q_{v}^{2}}{\pi^{2} R^{4}}\left(2-\frac{r^{2}}{R^{2}}\right)^{2}\left(1-\frac{r^{2}}{r^{\prime 2}}\right)^{2}-\frac{\zeta q_{v}^{2}}{\pi^{2} R^{4}}\left(1-\frac{r^{2}}{R^{2}}\right)^{2}\left(\frac{r^{2}-r^{\prime 2}}{R^{2}-r^{\prime 2}}\right)^{2}
\end{aligned}
$$

If $\eta=\sqrt{1-r^{2} / R^{2}}$ is the radius ratio of inner-outer tube, $\delta=r / r^{\prime}$ is denoted as the radius ratio of the inner flow passage, and $\delta^{\prime}=\sqrt{R^{2}-r^{2}} / \sqrt{R^{2}-r^{\prime 2}}$ is regarded as the equivalent radius ratio of the outer flow passage, $\Delta p$ can be simplified as:

$$
\Delta p=\frac{\rho}{2} \frac{q_{v}^{2}}{\pi^{2} R^{4}}(a-b)
$$

where $a=\left(1+\eta^{2}\right)^{2}\left[1-\delta^{4}+\varphi\left(1-\delta^{2}\right)^{2}\right]$;

$$
\begin{aligned}
& b=\eta^{4}\left[1-\delta^{\prime 4}+\zeta\left(1-\delta^{\prime 2}\right)^{2}\right] ; \\
& \varphi=\lambda\left[1-\left(1-\eta^{-2}\right)^{2}-\kappa\left(2-\eta^{-2}\right)\right] /[8 \sin (\theta / 2)] ; \\
& \zeta=\lambda\left[1-\left(1-\eta^{-2}\right)^{2}\right] /[8 \sin (\theta / 2)] .
\end{aligned}
$$

And the volume flow of $q_{v}$ can be also simplified as:

$$
q_{v}=\frac{\pi R^{2}}{\sqrt{a-b}} \sqrt{\frac{2 \Delta p}{\rho}}=C \cdot S \sqrt{\frac{2 \Delta p}{\rho}}
$$

where $S$ is the area of round pipe, $S=\pi R^{2} ; C$ is the discharge coefficient of the inner-outer tube,

$$
C=\frac{1}{\sqrt{a-b}}
$$

Based on (25), we can express $C$ as the calibration expression,

$$
C=\frac{q_{v}}{S \sqrt{2 \Delta p / \rho}}=\frac{\bar{v}}{\sqrt{2 \Delta p / \rho}}
$$

where $\bar{v}$ is the average flow velocity of the round pipe, $\bar{v}=q_{v} / S$.

Seen from (25), the relation between the volume flow and differential pressure depends mainly on three factors, namely, the big radius $r^{\prime}$, the small radius $r$, and the cone angle $\theta$, and can be independent of the fluid pressure. On one hand, these factors can be regarded as the structural parameters to design the inner-outer tube throttle flowmeter. On the other hand, they have significant influence on the differential pressure of inner-outer tube in complex flow states, although the expressions above are derived from the condition of laminar flow. 


\section{SIMULATION AND ANALYSIS OF FLOWMETER}

\section{A. Orthogonal test}

To find the best performance of the inner-outer tube throttle flowmeter, those 3 factors should be considered to design the orthogonal test. The test times will be quite long when a comprehensive test is carried out. Considering 3 factors at 3 levels full test, we need as many as $3^{3}=27$ test times, which will increase test difficulty so much that the comprehensive test cannot be conducted effectively. Therefore, the orthogonal test method can be used to find the best combinational plan effectively when using partial and representative points to replace full test points. Taking 3 factors-levels test as an example, an orthogonal test needs only 9-group tests instead of 27-group tests, which will greatly reduce the test work.

Based on the orthogonal test design theory, 3 factorslevels test plan with $L_{9}\left(3^{4}\right)$ orthogonal table was carried out to design the structure parameters of the inner-outer tube, such as the small radius $r$, the big radius $r^{\prime}$, and the cone angle (called also the diffusion angle) $\theta$.

The type of tested fluid pipe is U-PVC $32 * 2.4$. That is, the outer radius of pipe is $16 \mathrm{~mm}$ and the inner radius is 13.6 $\mathrm{mm}$. According to the pipeline conditions, the big radius $\left(r^{\prime}\right)$ of inner-outer tube can change from 6 to $12 \mathrm{~mm}$, and the cone angle $(\theta)$ varies from $6^{\circ}$ to $8^{\circ}$. If taking directly 3 parameters as 3 factors to prepare the orthogonal test design, there may be some invalid plans where $r$ may be equal to or even greater than $r^{\prime}$. In order to avoid these unrealizable cases, the radius ratios, $\varepsilon=r / r^{\prime}<1$, can be defined to replace the small radius as the new factor for orthogonal test design. Table 1. shows these factors (named A, B and C) and their values of corresponding levels (1,2 and 3 ), and hence produces the $L_{9}\left(3^{4}\right)$ orthogonal table (Table 2.).

Table 1. Values of 3 factors at 3 levels.

\begin{tabular}{|l|l|l|l|l|}
\hline \multicolumn{2}{|l|}{ Factor } & $\mathbf{A}, \boldsymbol{\varepsilon}$ & $\mathbf{B}, \boldsymbol{r}^{\prime}(\mathbf{m m})$ & $\mathbf{C}, \boldsymbol{\theta}\left(^{\circ}\right)$ \\
\hline \multirow{3}{*}{ Level } & 1 & 0.5 & 6 & 6 \\
\cline { 2 - 5 } & 2 & 0.65 & 9 & 7 \\
\cline { 2 - 5 } & 3 & 0.8 & 12 & 8 \\
\hline
\end{tabular}

Table 2. Orthogonal test design of $L_{9}\left(3^{4}\right)$.

\begin{tabular}{|l|l|l|l|}
\hline Plan No. & $\mathbf{A}, \boldsymbol{\varepsilon}$ & $\mathbf{B}, \boldsymbol{r}^{\prime}(\mathbf{m m})$ & $\mathbf{C}, \boldsymbol{\theta}\left(^{\circ}\right)$ \\
\hline 1 & $1(0.5)$ & $1(6 \mathrm{~mm})$ & $1\left(6^{\circ}\right)$ \\
\hline 2 & 1 & $2(9 \mathrm{~mm})$ & $2\left(7^{\circ}\right)$ \\
\hline 3 & 1 & $3(12 \mathrm{~mm})$ & $3\left(8^{\circ}\right)$ \\
\hline 4 & $2(0.65)$ & 1 & 2 \\
\hline 5 & 2 & 2 & 3 \\
\hline 6 & 2 & 3 & 1 \\
\hline 7 & $3(0.8)$ & 1 & 3 \\
\hline 8 & 3 & 2 & 1 \\
\hline 9 & 3 & 3 & 2 \\
\hline
\end{tabular}

\section{B. Fluent simulation}

To calculate the differential pressure with the flowmeter parameters in Table 2., the computational fluid dynamics (CFD) method was adopted.

Gambit was used to establish 9 groups of 3-D models based on Table 2.; the unstructured tetrahedral grids were meshed (Fig.2.) to adapt to the complex model of innerouter tube; and finally the meshing model was imported to the Fluent software.

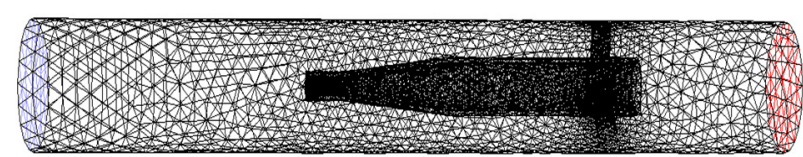

Fig.2. Meshing the inner-outer tube of Plan $1\left(\varepsilon=0.5, r^{\prime}=6\right.$ $m m, \theta=6^{\circ}$ ) with 109133 unstructured tetrahedral grids.

The pressure-based solver, absolute velocity equation and steady state flow were set as the basic setting of Fluent. The RNG-based $k-\varepsilon$ was treated as the turbulent model, because it is more accurate and reliable for a wider class of flows than the standard $k-\varepsilon[14]$. The water was used as the testing fluid in room temperature with the common velocity of $0.5 \sim 3.0 \mathrm{~m} / \mathrm{s}$ moving in the test pipe, whose minimal Reynolds number $\left(\mathrm{Re}_{\min }\right)$ was greater than the critical Reynolds number of round pipe $\left(\operatorname{Re}_{\mathrm{c}}=2000 \sim 2600\right)$,

$$
\operatorname{Re}_{\text {min }}=\frac{v_{\text {min }} d}{v}=\frac{0.5 \times 0.0272}{1.006 \times 10^{-6}}=13159>\mathrm{Re}_{\mathrm{c}}
$$

where $d$ is the internal diameter of the test pipe, $d=27.2 \mathrm{~mm} ; \quad v$ is the kinematic viscosity of water, $v=1.006 \times 10^{-6} \mathrm{~m}^{2} / \mathrm{s} ; v_{\min }$ is the minimum average inlet velocity, $v_{\min }=0.5 \mathrm{~m} / \mathrm{s}$.

For the incompressible fluid, the velocity inlet and outflow were set to the inlet and outlet of the boundary conditions, and the wall was set to both the throttle and pipe.

\section{Simulation results}

Fig.3. shows the differential pressure of the inner-outer tube and the anterior-posterior throttle, denoted as $\Delta p_{\text {io }}$ and $\Delta p_{\text {ap }}$, respectively, which were calculated under 6 velocities from 0.5 to $3.0 \mathrm{~m} / \mathrm{s}$. According to Fig.3., both $\Delta p_{\text {io }}$ and $\Delta p_{\text {ap }}$ increased with the increase of flow velocity. They were of a similar variation trend, and reached the relatively larger values when $r^{\prime}=12 \mathrm{~mm}$ (corresponding to Plans 3, 6 and 9) and the smaller values when $r^{\prime}=6 \mathrm{~mm}$ (equivalent to Plans 1,4 and 7).

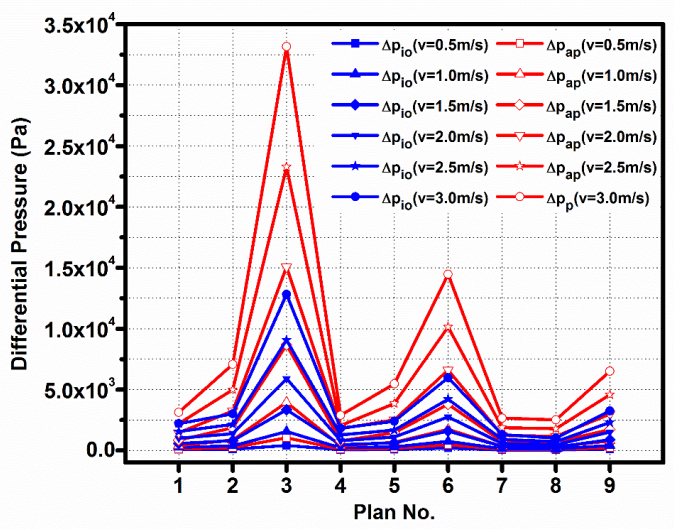

Fig.3. Differential pressure curves ( $\Delta p_{\text {io }}$ and $\left.\Delta p_{\text {ap }}\right)$ of 9 plans under different flow velocities from 0.5 to $3.0 \mathrm{~m} / \mathrm{s}$. 


\section{Analysis of variance}

If the flowmeter pursued only the biggest differential pressure of the inner-outer tube $\left(\Delta p_{\mathrm{io}}\right)$, differential pressure of the anterior-posterior throttle $\left(\Delta p_{\text {ap }}\right)$ would increase to the maximum value at the same time, which could cause a large increase of power cost. In order to achieve reasonable and economic parameters, both differential pressures should be considered simultaneously, and thus a dimensionless factor named the differential pressure ratio $\gamma$ was defined as,

$$
\gamma=\Delta p_{\text {io }} / \Delta p_{\text {ap }}
$$

Based on the defined factor and simulation results, the analysis of variance (ANOVA) was performed firstly. Table 3 provides the $F$ value of different factors, such as A, B and $\mathrm{C}$ (detailed meaning shown in Table 1.). Table 3. and Table 4. show three factors (A, B and C) had no significant differences under flow velocities of $3.0 \mathrm{~m} / \mathrm{s}$. The strange inference came from the non-merged factors, which caused the mean square less than that of the error (Table 4.).

Table 3. Result of ANOVA of differential pressure ratios under different flow velocities of $3.0 \mathrm{~m} / \mathrm{s}$.

\begin{tabular}{|c|c|c|c|c|}
\hline $\begin{array}{l}\text { Plan } \\
\text { No. }\end{array}$ & $\mathbf{A}$ & B & C & $\operatorname{Ratio}(\gamma)$ \\
\hline 1 & 1 & 1 & 1 & 0.707 \\
\hline 2 & 1 & 2 & 2 & 0.427 \\
\hline 3 & 1 & 3 & 3 & 0.387 \\
\hline 4 & 2 & 1 & 2 & 0.631 \\
\hline 5 & 2 & 2 & 3 & 0.44 \\
\hline 6 & 2 & 3 & 1 & 0.413 \\
\hline 7 & 3 & 1 & 3 & 0.491 \\
\hline 8 & 3 & 2 & 1 & 0.41 \\
\hline 9 & 3 & 3 & 2 & 0.499 \\
\hline$T_{1}$ & 1.521 & 1.829 & 1.530 & \multirow{4}{*}{$\begin{array}{l}\Sigma T=4.4050 \\
\Sigma \gamma^{2}=2.2525 \\
S_{T}=0.0965\end{array}$} \\
\hline$T_{2}$ & 1.484 & 1.277 & 1.557 & \\
\hline$T_{3}$ & 1.400 & 1.299 & 1.318 & \\
\hline$S S$ & 0.002563 & 0.065121 & 0.011422 & \\
\hline
\end{tabular}

Table 4. Details of ANOVA under velocities of $3.0 \mathrm{~m} / \mathrm{s}$.

\begin{tabular}{|l|l|l|l|l|}
\hline Factor & $\begin{array}{l}\text { Degree of } \\
\text { Freedom }\end{array}$ & $\begin{array}{l}\text { Stdev } \\
\text { Square }\end{array}$ & $\begin{array}{l}\text { Mean } \\
\text { Square }\end{array}$ & $\boldsymbol{F}$ \\
\hline A & 2 & 0.002563 & 0.001281 & 0.1477 \\
\hline B & 2 & 0.065121 & 0.032560 & 3.7532 \\
\hline C & 2 & 0.011422 & 0.005711 & 0.6583 \\
\hline Error & 2 & 0.017351 & 0.008675 & \\
\hline
\end{tabular}

Therefore, Factors A and C can be merged and appended to the error, because they seem to have no effect on the differential pressure ratio. Table 5. is the result of reanalysis of variance, where Factor B or the big diameter could be regarded as the significant factor. That is to say, the smaller the big diameter $r^{\prime}$ is, the bigger ratio of differential pressure can be achieved. This conclusion could be verified from the following Fig.4., where Plans 1, 4 and 7 achieved the bigger ratio because there was the smallest big diameter $\left(r^{\prime}=6 \mathrm{~mm}\right)$ in the plans above.

Table 5. Details of re-ANOVA under velocities of $3.0 \mathrm{~m} / \mathrm{s}$.

\begin{tabular}{|l|l|l|l|l|}
\hline Factor & $\begin{array}{l}\text { Degree of } \\
\text { Freedom }\end{array}$ & $\begin{array}{l}\text { Stdev } \\
\text { Square }\end{array}$ & $\begin{array}{l}\text { Mean } \\
\text { Square }\end{array}$ & $\boldsymbol{F}$ \\
\hline B & 2 & 0.065121 & 0.032560 & 6.2346 \\
\hline Error* & 6 & 0.031335 & 0.005223 & \\
\hline Sum & 8 & 0.096456 & $F_{1-0.05}(2,6)=5.14$ \\
\hline
\end{tabular}

\section{E. Range analysis}

From the intuitive view, the level $\mathrm{A}_{1} \mathrm{~B}_{1} \mathrm{C}_{1}$ of Plan 1 seemed to reach the largest value of differential pressure ratio among 9 plans in Fig. 4.

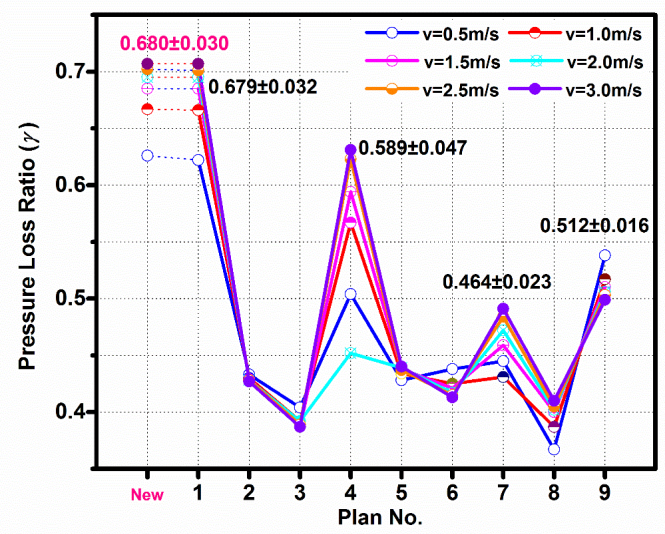

Fig.4. Pressure loss ratios of 9 plans under different flow velocities from 0.5 to $3.0 \mathrm{~m} / \mathrm{s}$.

However, the deduced new level of $\mathrm{A}_{1} \mathrm{~B}_{1} \mathrm{C}_{2}$.might reach a larger value than Plan 1, after performing the range analysis (Table 6.) based on simulation results.

Table 6. Range analysis of differential pressure ratio under different flow velocities from 0.5 to $3.0 \mathrm{~m} / \mathrm{s}$.

\begin{tabular}{|c|c|c|c|c|}
\hline \multirow{2}{*}{$\begin{array}{l}\text { Velocity } \\
(\mathrm{m} / \mathrm{s})\end{array}$} & \multirow{2}{*}{$\begin{array}{l}\text { Range } \\
\text { Analysis }\end{array}$} & \multicolumn{3}{|c|}{ Factors } \\
\hline & & $\mathbf{A}$ & B & $\mathrm{C}$ \\
\hline \multirow{5}{*}{0.5} & Average $k_{1}$ & 0.487 & 0.524 & 0.476 \\
\hline & Average $k_{2}$ & 0.457 & 0.409 & 0.492 \\
\hline & Average $k_{3}$ & 0.450 & 0.460 & 0.426 \\
\hline & Range $R_{g}$ & 0.036 & 0.114 & 0.066 \\
\hline & Biggest level & 1 & 1 & 2 \\
\hline \multirow{2}{*}{$1.0 \sim 2.5$} & $\ldots$ & $\ldots$ & $\ldots$ & $\ldots$ \\
\hline & Biggest level & 1 & 1 & 2 \\
\hline \multirow{5}{*}{3.0} & Average $k_{1}$ & 0.507 & 0.610 & 0.510 \\
\hline & Average $k_{2}$ & 0.495 & 0.425 & 0.519 \\
\hline & Average $k_{3}$ & 0.467 & 0.433 & 0.439 \\
\hline & Range $R_{g}$ & 0.040 & 0.184 & 0.080 \\
\hline & Biggest level & 1 & 1 & 2 \\
\hline
\end{tabular}


Considering the test plans did not contain the new level of $\mathrm{A}_{1} \mathrm{~B}_{1} \mathrm{C}_{2}$, the corresponding simulation was performed more with $\theta=7^{\circ}, r^{\prime}=6 \mathrm{~mm}, \varepsilon=0.5$ under 6 velocities and the results are displayed in Fig.4. and Table 7. The final result showed that the average differential pressure ratio ( $\bar{\gamma}=0.680 \pm 0.030)$ in the new level of $\mathrm{A}_{1} \mathrm{~B}_{1} \mathrm{C}_{2}$ was slightly superior to Plan 1 , which validated that range analysis could find the optimal combination parameters with the help of carefully designed orthogonal test.

Table 7. Simulation results of best level $\mathrm{A}_{1} \mathrm{~B}_{1} \mathrm{C}_{2}$ under different flow velocities from 0.5 to $3.0 \mathrm{~m} / \mathrm{s}$.

\begin{tabular}{|c|c|c|c|}
\hline \multirow{2}{*}{$\begin{array}{l}\text { Velocity } \\
(\mathrm{m} / \mathrm{s})\end{array}$} & \multicolumn{3}{|c|}{$A_{1} B_{1} C_{2}: r=3 \mathrm{~mm}, r^{\prime}=6 \mathrm{~mm}, \theta=7^{\circ}$} \\
\hline & $\Delta p_{\text {ap }}(\mathbf{P a})$ & $\Delta p_{\text {io }}(\mathbf{P a})$ & $\gamma$ \\
\hline 0.5 & 114.3 & 71.5 & 0.626 \\
\hline 1.0 & 395.0 & 263.3 & 0.667 \\
\hline 1.5 & 841.3 & 576.4 & 0.685 \\
\hline 2.0 & 1447.0 & 1005.8 & 0.695 \\
\hline 2.5 & 2203.9 & 1547.4 & 0.702 \\
\hline 3.0 & 3115.7 & 2203.5 & 0.707 \\
\hline Average & 1352.9 & 944.7 & $0.680 \pm 0.030$ \\
\hline
\end{tabular}

\section{DISCUSSION}

\section{A. Discharge coefficient}

Aimed at the best level of $\mathrm{A}_{1} \mathrm{~B}_{1} \mathrm{C}_{2}$, the discharge coefficient could be fitted as the slope of a line connecting the root of differential pressure $\sqrt{\Delta p}$ with the flow velocity $v$ based on (27) in Fig.5.

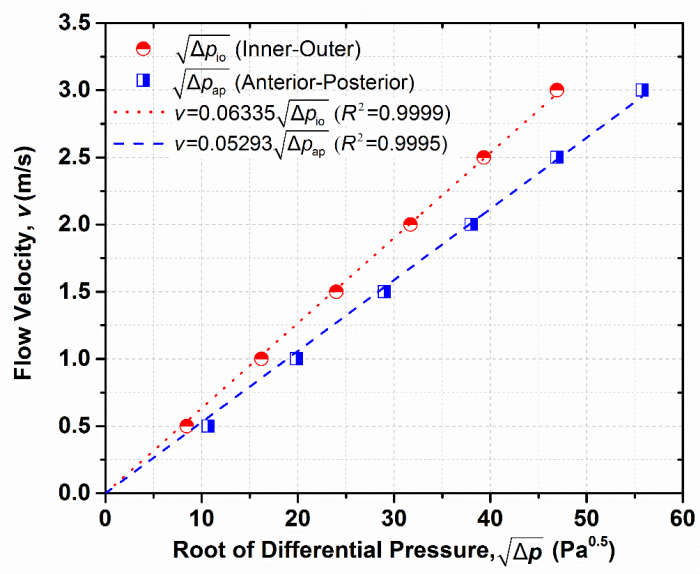

Fig.5. Discharge coefficient fitting based on the root of differential pressure and volume flow.

As the highest ratio of differential pressure, the optimal level of $\mathrm{A}_{1} \mathrm{~B}_{1} \mathrm{C}_{2}$ was used to estimate the discharge coefficient, shown in Fig.5. By fitting linearly between $Q_{v}$ and two kinds of root of differential pressure $\left(\sqrt{p_{\text {ap }}}\right.$ and $\left.\sqrt{p_{\text {io }}}\right)$, respectively, two slopes were in the same order of magnitude, $k_{\text {ap }}=0.05293$ for the anterior-posterior differential pressure and $k_{\mathrm{io}}=0.06335$ for the inner-outer one. According to (27), the discharge coefficients could be calculated as

$$
\begin{gathered}
C_{\text {ap }}=\frac{v}{\sqrt{2 \Delta p_{\text {ap }} / \rho}}=\frac{k_{\text {ap }}}{\sqrt{2 \rho}}=\frac{0.05293}{\sqrt{2 \times 998.2}}=1.1846 \times 10^{-3} \\
C_{\text {io }}=\frac{k_{\text {io }}}{\sqrt{2 \rho}}=\frac{0.06335}{\sqrt{2 \times 998.2}}=1.4178 \times 10^{-3},
\end{gathered}
$$

and

where the density of water at room temperature $\left(20^{\circ} \mathrm{C}\right)$ is $\rho=998.2 \mathrm{~kg} / \mathrm{m}^{3}$.

The calculation results meant two discharge coefficients $\left(C_{\text {ap }}\right.$ and $\left.C_{\mathrm{io}}\right)$ were in the same order of magnitude as well, but $C_{\text {io }}$ was larger than $C_{\text {ap }}$, which showed the sensitivity of the inner-outer tube as the measuring unit was better than that of the anterior-posterior throttle. Meanwhile, the fitting determination coefficient $\left(R^{2}=0.9999\right)$ of the former was slightly better than that of the latter $\left(R^{2}=0.9995\right)$. That is, the inner-outer tube is more competitive and more convenient in some special cases, especially in the limited space, because $\Delta p_{\text {io }}$ can be achieved only in the same section.

\section{B. Differential pressure comparison between anterior- posterior throttle and inner-outer tube}

The $\Delta p_{\text {ap }}$ of the anterior-posterior throttle should be as low as possible in virtue of the tremendous impact on the cost of the fluid transmission, while the $\Delta p_{\text {io }}$ of the inner-outer tube may be taken as a higher value because it can reduce the difficulty to measure the signal of differential pressure and decrease the investment cost. Therefore, $\Delta p_{\text {io }}$ and $\Delta p_{\text {ap }}$ can be maximized together to obtain the bigger $\Delta p_{\text {io }}$ and smaller $\Delta p_{\text {ap }}$ simultaneously. Furthermore, a dimensionless factor $f$ is defined in (28) to avoid different magnitude of differential pressures and reduce the effect of the different fluid velocities,

$$
f=\frac{\Delta p_{\text {io }}-\Delta p_{\text {ap }}}{\Delta p_{\text {ap }}}=\gamma-1
$$

Without considering the constant item, $f$ could be transformed to the differential pressure ratio $\gamma$ expressed in (28). As a result, the deduced level of $A_{1} B_{1} C_{2}$ could provide the best choice for the inner-outer tube flowmeter, corresponding to the largest $\gamma$.

The presented flowmeter adopted the inner-outer tube to obtain another differential pressure $\Delta p_{\text {io }}$ related to the flow velocity, other than the traditional differential pressure $\Delta p_{\text {ap. }}$. On one hand, the $\Delta p_{\text {ap }}$ range of $\mathrm{A}_{1} \mathrm{~B}_{1} \mathrm{C}_{2}$ was $110 \sim 3200 \mathrm{~Pa}$, obviously one order magnitude less than that of $\mathrm{A}_{1} \mathrm{~B}_{3} \mathrm{C}_{3}$ (Plan 3 in Fig.3.), and hence the power charge of the optimal level could be reduced significantly. On the other hand, the $\Delta p_{\text {io }}$ of the optimal level is more than twice that of Plan 8 (close to the smallest level). Thus, the measured signal $\Delta p_{\text {io }}$ can avoid high sensitivity of pressure sensor and decrease the manufacturing expenses of the inner-outer tube flowmeter because of the relatively large value of $\Delta p_{\text {io. }}$. 
As is known, $\mathrm{V}$-cone flowmeter has been one of the most popular throttle flowmeters in recent years, because of its good performance and low pressure loss. To compare with the inner-outer tube flowmeter presented in this paper, the $\mathrm{V}$-cone flowmeter was set to the parameters below based on the popular researches [15]-[16]. The length of $\mathrm{V}$-cone was $200 \mathrm{~mm}$, and the equivalent diameter ratio was $\beta=0.6$, and the diffusion angles were $60^{\circ}$ (anterior) and $150^{\circ}$ (posterior), respectively.

Using the same boundary conditions as those of the innerouter tube flowmeter, the differential pressure of the V-cone throttle in Fig.6. was compared with that of the inner-outer tube and anterior-posterior throttle under the same flow velocity. The simulation results showed that the sensitivity of $\mathrm{V}$-cone flowmeter was quite lower than that of the innerouter tube flowmeter (including $\Delta p_{\text {ap }}$ and $\Delta p_{\text {io }}$ as measuring unit). According to the data, the differential pressure of $\mathrm{V}$ cone $\left(\Delta p_{\text {V-cone }}\right)$ was about 16 times of $\Delta p_{\text {io }}$ under flow velocities varying from 0.5 to $3.0 \mathrm{~m} / \mathrm{s}$, and hence the slope of the output/input line for the $\mathrm{V}$-cone flowmeter was only a quarter of that for the presented flowmeter. It is no doubt that the inner-outer tube flowmeter can both reduce more operating cost than $\mathrm{V}$-cone, and increase the sensitivity to a great extent as the important factor for the flowmeter to use more widely.

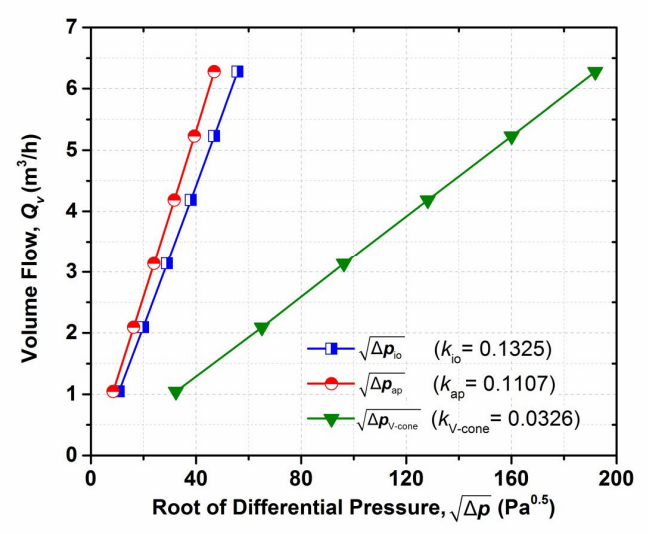

Fig.6. Comparison of anterior-posterior differential pressure between $\mathrm{V}$-cone flowmeter and inner-outer tube flowmeter.

\section{CONCLUSION}

Firstly, a throttle element of the inner-outer tube was designed and presented to solve the dilemma between the smaller differential pressure (or pressure loss) and the larger flow measurement signal in traditional throttle flowmeters. Secondly, the mathematical model was deduced theoretically based on the hydrodynamics, where there were three major parameters (big radius $r^{\prime}$, small radius $r$, and cone angle $\theta$ ) to determine the structure of inner-outer tube. Thirdly, using both $L_{9}\left(3^{4}\right)$ table of orthogonal test design and CFD of Fluent software, the optimal results were obtained by taking a defined ratio of the inner-outer differential pressure $\Delta p_{\text {io }}$ divided by the anterior-posterior one $\Delta p_{\text {ap }}$ as the optimization goal. Finally, the optimal simulation results $\left(r^{\prime}=6 \mathrm{~mm}, r=3 \mathrm{~mm}\right.$ and $\theta=7^{\circ}$ ) showed that the pressure loss of the anterior-posterior throttle could not only remain a smaller value among other parameters with the same structure, but was about one order magnitude less than that of $\mathrm{V}$-cone flowmeter in the similar installation conditions, when the flow velocity varied from 0.5 to $3.0 \mathrm{~m} / \mathrm{s}$. The lower pressure loss of $\Delta p_{\text {ap }}$ and relatively higher $\Delta p_{\text {io }}$ as the measured signal can save the manufacture costs and avoid the large sensitivity of pressure sensors, which may lead to a broader application in chemical and petrochemical enterprises.

\section{ACKNOWLEDGMENT}

The authors would like to acknowledge the support from the National Natural Science Foundation of China under Grant no. 61401406 and no. 50871086.

\section{REFERENCES}

[1] Schena, E., Massaroni, C., Saccomandi, P., Cecchini, S. (2015). Flow measurement in mechanical ventilation: A review. Medical Engineering \& Physics, 37 (3), 257-264.

[2] Thorn, R., Johansen, G.A., Hjertaker, B.T. (2013). Three-phase flow measurement in the petroleum industry. Measurement Science and Technology, 24 (1), 12003-12019.

[3] Jiang, W., Zhang T., Xu, Y., et al. (2016). The effects of fluid viscosity on the orifice rotameter. Measurement Science Review, 16 (2), 87-95.

[4] Fincham, A.M., Spedding, G.R. (1997). Low cost, high resolution DPIV for measurement of turbulent fluid flow. Experiments in Fluids, 23 (6), 449-462.

[5] Santi, P.M. (2014). Precision and accuracy in debrisflow volume measurement. Environmental \& Engineering Geoscience, 20 (4), 349-359.

[6] Daev, Z.A. (2015). A comparative analysis of the discharge coefficients of variable pressure-drop flowmeters. Measurement Techniques, 58 (3), 323326.

[7] Nukui, K., Komiya, K., Kagawa, T. (2009). Effect of temperature sensor position on differential pressure measurement in orifice type flowmeter. Journal of Clinical Psychopharmacology, 38 (3), 233-238.

[8] Xu, L., Zhou, W., Li, X., et al. (2011). Wet-gas flow modeling for the straight section of throat-extended Venturi meter. IEEE Transactions on Instrumentation and Measurement, 60 (6), 2080-2087.

[9] Nithin, T., Jain, N., Hiriyannaiah, A. (2012). Optimization of Venturi flow meter model for the angle of divergence with minimal pressure drop by computational fluid dynamics method. In International Conference on Challenges and Opportunities in Mechanical Engineering, Industrial Engineering and Management Studies (ICCOMIM 2012), July 11-13, 2012, 658-670.

[10] Wei, C., Tan, Ch., Dong, F. (2011). Numerical simulation and optimal design for cone flowmeter. Journal of Engineering Thermophysics, 32 (7), 11651168. 
[11] Daev, Zh.A. (2015). A comparative analysis of the discharge coefficients of variable pressure-drop flowmeters. Measurement Techniques, 58 (3), 323326.

[12] Guo, S., Sun, L., Zhang, T., Yang, W., Yang, Z. (2013). Analysis of viscosity effect on turbine flowmeter performance based on experiments and CFD simulations. Flow Measurement \& Instrumentation, 34 (5), 42-52.

[13] Sleigh, A. (2009). Real fluids - Pressure loss during laminar flow in a pipe. University of Leeds, UK, http://www.efm.leeds.ac.uk/CIVE/CIVE1400/Section4 /laminar turbulent.htm.

[14] Mihailovic, D.T., Gualtieri, C. (Editors) (2010). Advances in Environmental Fluid Mechanics. World Scientific Publishing Company, ISBN 978-981-446597-7.
[15] Thorel, L., Gaudin, C., Rault, G., Garnier, J., Favraud, C. (2007). A cone pressuremeter for soil characterisation in the centrifuge. International Journal of Physical Modelling in Geotechnics, 7 (1), 25-32.

[16] Xu, Y., Chen, W., Zhang, T., Liu, W. (2015). Study on applicability of turbulence model for V-cone flowmeter with double support. Chinese Journal of Scientific Instrument, 36 (2), 459-465.

Received November 11, 2016. Accepted March 13, 2017. 